\title{
Els signes distintius de les denominacions d'origen vitivinícoles catalanes. Contextualització històrica
}

The distinctive signs of designations of origin for Catalan wine. Historical contextualization

Los signos distintivos de las denominaciones de origen vitivinícolas catalanas. Contextualización histórica

Gemma Molleví Bortoló ${ }^{1}$

Jordi Villoro Armengol

\section{Resum}

L'objectiu d'aquest article és valorar la relació entre la història de la vitivinicultura a Catalunya i les denominacions d'origen (DO) catalanes mitjançant les seves marques significatives.

L'origen de la vitivinicultura catalana es remunta a la cultura ibera pels contactes fenicis i grecs, es consolidà amb els romans i s'expandí durant l'edat mitjana. Algunes zones esdevingueren DO que reforcen el vincle geogràfic amb el territori on es produeix el vi de qualitat. Algunes d'elles mostren aquest origen històric en els seus signes distintius: amb els grecs (DO Empordà), amb els romans (DO Tarragona) o amb el període medieval (DOQ Priorat).

Paraules clau: Història vitivinícola, Catalunya, DO, signes distintius.

\footnotetext{
Abstract

The aim of this article is to assess the relationship between the history of viticulture in Catalonia and the Catalan Designations of Origin (DO) through their significant brands.

The origins of Catalan viticulture go back to Iberian culture through Phoenician and Greek contacts, consolidation with the Romans, and expansion during the Middle Ages.

1. ORCID: 0000-0002-5341-8545. ESIC Business \& Marketing School. Barcelona. Correu electrònic: gemma.mollevi@ esic.edu.

2. 0000-0003-2145-5795. ESIC Business \& Marketing School. Barcelona. Correu-e: jordi.villoro@esic.edu.

Rebut: III/2021. Avaluat: VIII/2021. Versió definitiva: IX/2021
} 
Some areas became DOs that strengthen the geographical link with the territory where quality wine was produced. Some of them show this historical origin in their distinctive brands, for example, the Greeks (DO Empordà), the Romans (DO Tarragona), or the medieval period (DOQ Priorat).

Keywords: Viticulture and wine history, Catalonia, Designations of Origin, brands.

\section{Resumen}

El objetivo de este artículo es valorar la relación entre la historia de la vitivinicultura en Cataluña y las Denominaciones de Origen (DO) catalanas mediante sus sellos identificativos.

El origen de la vitivinicultura catalana se remonta a la cultura íbera por los contactos fenicios y griegos, se consolida con los romanos y se expande durante la Edad Media. Algunas zonas se convirtieron en DO reforzando el vínculo geográfico con el territorio donde se produce el vino de calidad. Algunas de ellas muestran este origen histórico en sus signos distintivos: con los griegos (DO Empordà), con los romanos (DO Tarragona) o con el período medieval (DOC Priorat).

Palabras clave: Historia vitivinícola, Cataluña, DO, signos distintivos.

\section{Objectiu de la recerca}

Amb aquest article ens volem apropar a l'estudi històric de les denominacions d'origen (DO) i l'activitat vitivinícola que han desenvolupat les diferents societats que han viscut al territori i comercialitzat a través de la Mediterrània. I verificar que en algunes d'aquestes DO les marques figuratives que es fan servir per a la presentació i expedició dels vins produits dins del territori sota la indicació de qualitat recorden fets històrics. L'objectiu és valorar en quants segells hi ha reflectit un motiu històric i veure si es tracta del mateix període històric o si corresponen a més d'un. Considerem important que, encara avui, un producte vinícola de qualitat es relacioni directament amb els fets històrics en què es va emmarcar a l'origen, a banda d'altres aspectes més comercials, geogràfics o artístics.

\section{Introducció: les denominacions d'origen com a marques comercials}

La vitivinicultura estava present en la cultura ibera pels contactes fenicis i grecs, i es va consolidar com a tal amb l'establiment romà. Tradicions, gastronomia, llengua, arts i espiritualitat es van difondre pel territori a través de la societat que vivia en aquelles contrades, i ho van fer per via marítima: Emporion, Barcino i Tarraco van ser els ports més importants. 
Posteriorment, l'expansió vitivinícola a Catalunya durant els segles ix i x va ser deguda a la cristianització de la societat i a l'establiment dels monestirs en zones que a la llarga esdevingueren regions importants per al cultiu de la vinya i la producció de vins de renom, com els de Sant Pere de Rodes, Santa Maria de Poblet i la cartoixa de Santa Maria d'Escaladei. En alguns casos, es van establir en llocs on ja s'havien ubicat els pobles grecoromans, però també en llocs nous que actualment són DO: DO Empordà, DO Conca de Barberà i DO Qualificada Priorat.

Posteriorment, regions que havien quedat al marge o havien perdut la seva influència van potenciar el desenvolupament vitícola amb nous productes gràcies a la destillació, que van agafar empenta amb el descobriment d'Amèrica i l'expansió d'ultramar. En aquest context, també cal destacar altres cicles vitivinícoles que es van anar produint, com ara el conreu de la vinya a tota mena de contrades gràcies a la construcció de terrasses amb l'arribada de la filloxera a França i l'abandonament d'aquestes mateixes terres quan la plaga va arribar a Catalunya.

Un nou període es va obrir, llavors, amb la reducció de les plantacions de vinyes, el treball de les estacions enològiques per trobar les millors varietats mixtes per a cada territori, l'aparició d'escoles agràries i el moviment cooperativista. Tot plegat va concretar l'existència d'unes regions vitivinícoles singulars arreu del territori català.

D'aquesta manera, el 1932, la llei estatal del vi ja incloïa un apartat que reglamentava les DO. Les denominacions d'origen permeten presentar al mercat un producte agroalimentari de qualitat emparant-se en unes pautes generals estrictes tant pel que fa al conreu de la vinya com a l'elaboració del vi. Permeten protegir el productor vitícola i vinícola d'altres vins elaborats amb mesures de producció diferents i alhora el consumidor, per evitar que li arribin productes fraudulents. Aquesta delimitació es fa a partir de les vinyes que són la base del producte i que estan vinculades amb un sòl amb característiques pròpies; el vi serà únic perquè s'ha fet en un lloc en concret amb les seves particularitats i singularitats físiques (sòl, clima, relleu, insolació) i humanes (combinacions de raïms de diferents varietats en diferents graus). Per tant, la DO presenta al mercat un producte vinícola d'una regió determinada que s'engloba en una collectivitat a partir d'una singularitat que les identifica. Pertànyer a la DO implica facilitats per cobrir un sector del mercat que fa demanda de productes d'alt valor afegit i amb un grau elevat d'identitat territorial. És una entitat jurídica, reglamentada a partir de fets objectius i mesurables, a més de factors patrimonials, collectius, tradicionals i culturals.

La DO dona molta importància al seu signe distintiu, és a dir, al dibuix del logotip que acompanya tots els seus vins i que d'alguna manera n'esdevé la marca figurativa comercial. I aquest article se centra principalment a valorar el disseny dels logotips de les DO catalanes vitivinícoles i el seu significat, per trobar-hi relacions i saber si en el punt de partida del dibuix del segell de la DO hi predomina el vessant històric, geogràfic, toponímic, artístic o d'una altra mena. I és el cas que algunes de les DO mostren l'origen històric en el seu signe distintiu: amb la població grega (DO Empordà), amb la població romana (DO Tarragona), amb els monestirs medievals (DOQ Priorat) o amb l'orde del Temple (DO Conca de Barberà), entre d'altres. 


\section{Metodologia, fonts d'informació i camp d'estudi}

Les fonts d'informació usades per a la realització d'aquest article científic són la recerca bibliogràfica, les dades obtingudes a partir de l'INCAVI —organisme gestor de les DO catalanes- $\mathrm{i}$ la informació aportada per les mateixes denominacions d'origen en referència al disseny del seu segell.

El camp d'estudi és Catalunya i els segells de les DO són: Alella, Catalunya, Conca de Barberà, Costers del Segre, Empordà, Montsant, Penedès, Pla de Bages, Priorat, Tarragona, Terra Alta. Podem localitzar les deu DO en el mapa 1, llevat de la DO Catalunya perquè més o menys se superposa a les deu anteriors.

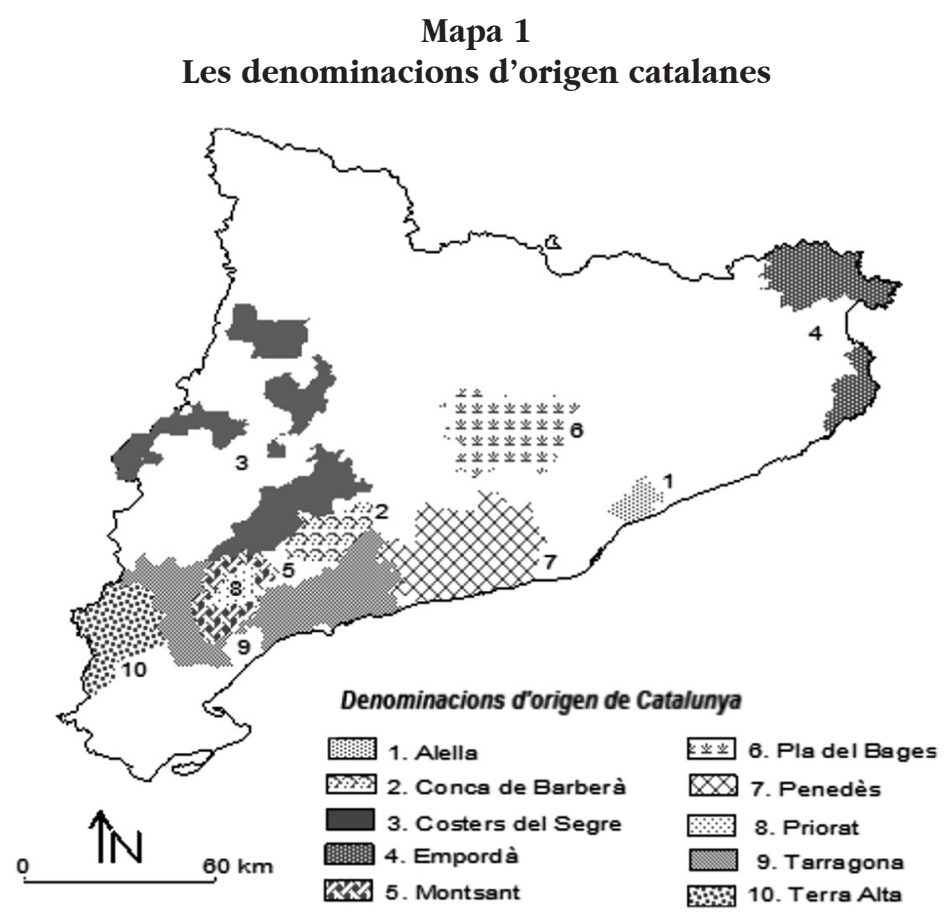

Font: Reglaments de les denominacions d'origen i INCAVI

La història de la vitivinicultura a Catalunya és millenària; del conreu de la vinya i la producció de vi se'n troben vestigis en jaciments arqueològics en diferents punts del territori català. Els pobles fenicis ja comercialitzaven amb la població local, i es creu que aquests contactes comercials van facilitar la transmissió de coneixements. Per tant, no és estrany pensar que ja la població ibèrica coneixia el vi i com elaborar-ne, encara que devia ser de manera testimonial i en quantitats reduïdes. Justament per aquesta raó va ser important l'arribada dels grecs a l'Empordà, perquè s'hi installaren i conrearen vinyes més extensi- 
vament i van arribar a produir un vi que era part cultural important de la cultura grega, ja que es trobava associat, com l'oli, a les creences i les festes dels seus habitants. Els romans acabaren de fer expandir la vitivinicultura a Catalunya pel fet que van impulsar el conreu de la vinya i la producció de vi en grans quantitats, no només per abastir la població local, sinó també per exportar a altres regions de l'Imperi i fins i tot a la capital, Roma, on els vins de la Tarraconense eren molt preuats.

Amb la caiguda de l'Imperi romà, no es va deixar de fer vi, però sí que hi va haver una reducció tant en la plantació de vinyes com en la producció i la comercialització de vins. S'hagué d'esperar a l'arribada dels monjos provinents de diferents monestirs d'Europa que s'anaren installant en diferents contrades menys o més aptes per al conreu i en les quals la producció de vi era essencial per al seu consum diari, fins al punt que els excedents els permetien crear una gran xarxa comercialitzadora i algunes zones van guanyar prestigi. També els senyors feudals, juntament amb l'orde del Temple, van permetre l'expansió del sector vitivinícola en els seus dominis i al voltant dels castells, aprofitant que el vi aportava molts nutrients i tenia usos medicinals i religiosos, de manera que formava part de la dieta diària. Posteriorment, un altre moment clau en la història del sector va tenir lloc durant l'edat moderna (Valls, 2003, amb la comercialització amb Europa i el descobriment d'Amèrica, ja que es feia imperiós produir vi i aiguardent per al consum en les grans travessies: durant aquests viatges era més recomanable que l'aigua pel fet que es tractava d'una beguda fermentada i destillada. Les destilleries i els ports comercials de Catalunya van guanyar gran protagonisme i qualsevol tros de terra era útil per conrear vinyes per fer-hi vi o aiguardent, la qual cosa permetia una més llarga conservació. Va ser el moment àlgid en la plantació de vinyes arreu del territori català, i fins i tot es va arribar als Pirineus. Amb tot, la filloxera va acabar afectant també Catalunya i va arrasar totes les plantacions vitícoles. La posterior reconstrucció del sector es va fer sobretot amb el moviment cooperativista, amb la selecció de plantes mixtes de peu americà que eren immunes a l'insecte i amb la creació d'estacions enològiques que permeteren decidir quines eren les millors vinyes per a cada zona alhora que transmeteren els nous coneixements vitícoles i enològics. Per finalitzar aquesta breu història del sector vitivinícola a Catalunya (Ciurana, 1980; Molleví, 2007; Rexach, 2000) cal fer referència a l'entrada d'Espanya a la Unió Europa, que va implicar la potenciació de la producció de vins de qualitat i la penalització de les grans superfícies vitícoles. Interessava més fer productes manufacturats amb identitat, reglamentats en petites quantitats i embotellats i menys en grans produccions vinícoles de vins a granel i que omplien d'estocs el mercat. En el cas de Catalunya es va enfortir la creació de denominacions d'origen, que cobreixen quasi tot el territori del país amb personalitats i particularitats ben diferenciades.

A partir dels dissenys dels segells actuals de cada una de les DO estudiades per la seva significació, i la redacció del resum històric del sector vitivinícola a l'actual Catalunya que acabem d'apuntar, valorarem els possibles nexes comuns entre els dos factors: el de la imatge i el de la història. Per tant, s'han establert dos grans grups històrics, els de l'edat antiga -Ibèria, Grècia i Roma- i els de l'edat mitjana —ordes religiosos francesos i orde del Temple. 


\section{Els primers orígens vitivinícoles a l'edat antiga a Catalunya: civilitzacions iberes, fenícies, gregues i romanes}

Abans de l'arribada i la installació dels pobles mediterranis grecs i romans, la civilització ibera ja feia vi, i probablement aquesta elaboració era intensificada pels intercanvis econòmics i de coneixements amb pobles marítims com els fenicis. Amb l'arribada i la installació de les colònies gregues en terra catalana es començà a introduir de manera destacable el conreu de la vinya i la producció del vi, per bé que els majors impulsors i difusors de l'agricultura vitícola, de la producció de vi a Catalunya i, en especial, de la seva comercialització per tot l'Imperi foren els romans.

Per això hem agrupat en un sol apartat, el considerat corresponent a l'edat antiga, els tres vestigis més importants del naixement de la vitivinicultura catalana: la ibera, la grega i la romana. Per tant, encara que ja s'hi feia vi abans de l'arribada dels grecs, la consolidació del conreu més intensiu vitícola i la producció de vi es va introduir amb la installació de les colònies gregues, i l'expansió vitícola i la comercialització fora de les terres catalanes es va fer amb els romans. És un gran període que té en comú la mar Mediterrània.

\section{La presència de la vitivinicultura en la Catalunya ibera}

A partir de jaciments arqueològics de poblacions iberes (segles viI $\mathrm{aC}$-I $\mathrm{dC}$ ) és possible saber com vivien, de què s'alimentaven, quins rituals tenien i com es vestien. Per tant, en aspectes vitivinícoles, es pot afirmar que els habitants que poblaven el territori de l'actual Catalunya abans de l'arribada dels grecs i els romans ja coneixen les vinyes i les havien après a conrear.

En primer lloc, la societat ibera consumia el raïm com a fruita del temps o seca (Celestino, 2007), però, a més, també consumia vi i cervesa (d'aquesta, en més quantitat). I justament perquè la cervesa estava més present en totes les capes socials, el vi tenia un rang social més elevat. Les quantitats de vi disponible podien ser elevades ja des del segle vi aC gràcies a la producció local (Quesada, 1994). El consum de vi s'associava a banquets, estava present en rituals i participava de situacions excepcionals: moments abans d'entrar en batalla, i funerals, per exemple.

Posteriorment, amb el contacte inicial amb pobles mariners i comercials com ara etruscs i fenicis, la producció de vi s'intensificà. Amb l'arribada dels grecs, és probable que aquests pobladors coneguessin més bé l'aportació de nutrients d'aquesta beguda i en milloressin la producció tot augmentant-ne la quantitat i la qualitat. Durant aquests primers contactes comercials entre els ibers amb els fenicis i els grecs, no només s'hi traslladaren coneixements dels uns als altres, sinó que també es conegueren usos i formes de vestir, de menjar i beure, de celebració i d'expressivitat religiosa i funerària. Així, als jaciments arqueològics ibers s'observa la presència d'una associació entre els segles vi i v aC d'àmfora fenícia per conservar el vi i copa grega per consumir-ne, amb un motiu tradicional en el primer cas i amb caràcter prestigiós en el segon (Celestino, 2007). 
En aquests jaciments repartits al llarg del litoral i al voltant dels rius (Empordà, Penedès/Garraf, Francolí/Gaià i Ebre) hi trobem restes relacionades amb la producció, la comercialització i el consum de vi a les zones de l'Escala (Empordà), Turó de la Font de la Canya (Avinyonet del Penedès) i a Alcanar (Montsià), entre d'altres.

\section{La consolidació del conreu de la vinya i la producció de vi amb el poble grec}

Com ja hem apuntat, els grecs van introduir el conreu de la vinya per a la producció de vi a la Catalunya actual a partir de les seves colònies, començant per la d'Empúries a la comarca de l'Empordà. La tradició grega es basava en la seva idea d'expansió territorial: una metròpolis i un seguit de colònies - ciutats-que depenien en un inici de la metròpolis i que a la llarga esdevenien autosuficients. L'expansió la feien a través de la Mediterrània, amb vaixells, i s'installaven tant al continent com a les illes. Les llavors les portaven amb ells i s'installaven en algun lloc proper a la costa, de manera sedentària, conreant i pasturant, alhora que establien relacions comercials i d'intercanvi amb la població indígena.

Aquests exploradors grecs van arribar a la costa empordanesa amb uns vaixells de forma arrodonida fets de fusta (de pi i xiprer) amb una vela quadrada de lli, resistent i flexible, lligada al llarg d'un sol pal. Es van installar a la polis Emporion, que vol dir «mercat», al 218 aC. Van començar a establir relacions amb la població local intercanviant no només objectes i productes, sinó el que és més important, coneixements. La ciutat d'Emporion estava emmurallada, excepte davant la costa, on hi havia el port o punt de desembarcament; estava creuada per dos carrers principals que confluien a la part central a la plaça o àgora, i allà se celebraven el mercat i les reunions públiques. El mercat grec és molt semblant als mercats de tants pobles catalans actuals, que han perdurat fins als nostres dies (Molleví, 2007).

La seva presència es va allargar durant els segles vi aC i II aC i van establir altres assentaments, com el de Roses. Transformaven matèries primeres en objectes artesanals que tenien gran acceptació entre la població local; importaven joies, teixits i perfums, també oli i vi, i els canviaven per matèries primeres com ara metalls i pedres precioses. Els pobles, tal com hem comentat pel que fa a Empúries, estaven envoltats de camps de conreu amb blat, oliveres, ametllers i vinyes, és a dir, de cultura mediterrània, per produir fruita seca i de temporada, vi i oli, que feien servir no només per alimentar-se sinó també per a rituals i ofrenes.

Cap al final del període grec a Catalunya, les polis gregues ja eren capaces de generar excedents per iniciar una incipient comercialització de productes, com és el cas de l'oli i el vi, que es traslladaven en àmfores cap a França i altres parts de la península Ibèrica per via marítima.

Probablement, els grecs portaren els sarments originals de Grècia, però devien trobar també les menes silvestres del lloc i devien fer-ne ús i fins i tot provar de barrejar-les. El vi es feia fermentar a l'interior de les àmfores i també es conservava, traslladava i consumia a partir de la mateixa àmfora. En aquell moment, la Mediterrània estava dominada pel po- 
ble cartaginès, el grec, l'etrusc i el fenici, i cada un d'ells tenia la seva àrea de preferència i influència on els altres no entraven. Aquesta situació va finalitzar el segle II aC amb l'Imperi romà.

\section{L'expansió vitivinícola catalana durant l'Imperi romà}

Estrabó ( $58 \mathrm{aC}-21 / 25 \mathrm{dC}$ ), geògraf grec, va visitar l'extens territori que formava llavors l'Imperi romà i ho va reflectir en la seva obra Geografia. Lògicament, va esmentar el vi ibèric, i com a espais de producció va destacar les costes sud i est, en contacte amb la mar Mediterrània. A més, afirmava que la vitivinicultura es podia fer a tota la península Ibèrica.

Plini el Vell, erudit llatí ( $23 \mathrm{dC}-79 \mathrm{dC})$ va redactar una Història Natural molt completa que recollia diferents plantes i arbres fruiters i dedicava tot un capítol dels 23 que formen l'obra a qüestions vitivinícoles. Precisament en el capítol XIV considerava la vinya com a arbre fruiter, i hi explicava com s'havia de conrear, quines menes de vinyes hi havia, com es feien els diferents vins i com s'havien de conservar, i quins efectes nocius tenia beure massa vi. També localitzava les àrees vitivinícoles i destacava els vins ibers, especialment els que es feien a la costa que va des de l'actual ciutat de Barcelona fins a la actual ciutat de València, és a dir, la costa oriental de la mar Mediterrània, amb semblança al que ja havia dit Estrabó.

Sili Itàlic ( $25 \mathrm{dC}-101 \mathrm{dC})$, en el seu llibre sobre les conquestes de l'Imperi romà, Púni$c a$, també menciona l'àrea de Tarragona com una de les més importants de l'Imperi i en destaca la seva gran producció i la qualitat dels seus vins. I també, utilitzant les metàfores i la poesia, Marc Valeri Marcial (40-104 dC), nascut a Calatayud, defensava els vins fets a Tarragona, els quals competien per ser comptats entre els millors de l'Imperi.

En un estudi de 1988, Jordi Miró recollia les poblacions catalanes que tenien forns per fer les àmfores vinícoles durant el període romà, els tipus d'àmfores que es feien, els ports d'on sortien els vaixells carregats amb el vi produit a Catalunya i els llocs arreu d'Europa on s'han trobat restes arqueològiques d'aquestes àmfores fetes a Catalunya. Així, els ports dels quals sortien els vaixells carregats d'àmfores vinícoles són, de nord a sud, l'antiga ciutat d'Empúries i les actuals ciutats de Roses, Blanes (Blandae), Mataró (Iluro), Badalona (Baetulo), Barcelona (Barcino), Tarragona (Tarraco) i Tortosa (Dertosa). Els forns es localitzaven en aquestes mateixes ciutats portuàries, en ciutats properes o en ciutats més allunyades a les portuàries, però comunicades pels rius Ter, Besòs (hi ha restes arqueològiques de forns a Caldes de Montbui, Llinars del Vallès, Cerdanyola del Vallès i Sabadell), Llobregat (amb restes de forns a Sant Boi de Llobregat, Castellbisbal i el Papiol) i l'Ebre. Les àmfores que es feien a Catalunya són les de tipus Dressel 1 Layetana, la Tarraconense 1 (també anomenada Laietana 1), la Pascual 1, la Dressel 2-4, l'Oberaden 74 i la Dressel 7-11. I les destinacions del vi que es feia a Catalunya eren ben diverses per tot el continent europeu, ja que s'han trobat restes d'àmfores fetes a Catalunya a la resta de províncies espanyoles, a Portugal, França, Itàlia, Suïssa, Alemanya, Gran Bretanya i Luxemburg. 
En el llibre d'Alain Huetz de Lemps (2009) sobre els vins d'Espanya hi ha un mapa de les dues àrees vitivinícoles més importants en l'època romana: la Bètica, a la zona de les actuals ciutats de Jerez de la Frontera i Cadis, i la Tarraconense, que, des de les actuals ciutats de Girona fins a València, resseguia tota la costa est d'Espanya. Al mateix temps, s'indiquen les àmfores més conegudes que es feien a Espanya en aquells moments: la Púnica, la Dressel 1, la Pascual 1, la Dressel 2-4, la Haltern 70 i la Tarraconense 1. Amb les informacions aportades per les excavacions arqueològiques i amb la lectura dels textos escrits en aquells moments es fa palesa la situació vitivinícola a la península en la època romana, concentrada en un primer moment a la costa mediterrània, però més àmplia cap a les terres de l'interior a mesura que la romanització de la península Ibèrica s'anava ampliant.

Finalment, en els museus s'hi poden trobar diverses restes arqueològiques que demostren la importància que tenia el vi a la Catalunya romana. D'exemples n'hi ha al Museu Nacional Arqueològic de Tarragona (Museu Nacional Arqueològic de Tarragona, 1998) i al Museu d'Història de la Ciutat de Barcelona (Heredia Bercero, 2001). En el primer cas, es constata que el vi era consumit en els àpats més festius, i s'hi exposen diferents objectes com ara vaixelles amb copes i gerres per servir el vi, les mencionades àmfores per transportar el vi i l'oli de la Hispània romana a la capital, Roma, i fins i tot les barriques de fusta que substituïren les àmfores en el transport vinícola. En el cas del Museu d'Història de la Ciutat de Barcelona, justament, s'hi ha trobat un celler amb restes de grans cisternes de ceràmica on es conservava el vi, i canalitzacions que duien el most des d'allà on es premsava el raïm fins on es deixava fermentar. Aquesta troballa és molt important perquè ha permès establir tot el procés de vinificació que realitzaven els romans per produir un dels seus béns més estimats; d'altra banda, cal dir que no diferia gaire del procés actual.

Les àmfores trobades als jaciments arqueològics ofereixen molta informació sobre el cultiu de la vinya i la producció de vi, perquè indiquen la localització de la producció vinícola, la localització dels forns de fabricació d'àmfores destinades a l'exportació, els llocs de consum i les rutes comercials establertes en aquell moment.

El ja esmentat treball de recerca realitzat per J. Miró (1988) inclou un llistat dels forns de fabricació d'àmfores i dels ports d'exportació, a partir del qual es va elaborar el mapa 2, que proporciona detalls de gran interès. Així, es constata que els forns se situaven prop del litoral, és a dir, prop dels ports d'embarcament, però també a l'interior, al llarg dels rius. Durant l'Imperi romà, el transport era sobretot fluvial i marí, ja que la via terrestre resultava deficient, a excepció de les grans rutes creades per unir les capitals amb la ciutat imperial, com era el cas de la Via Augusta. Pel que fa al vi, el desconeixement en aquell moment de tècniques de conservació òptimes afavorí el transport amb barques o vaixells. Quan el vi era de bona qualitat s'enviava en àmfores, però quan era de mala qualitat es transportava en barriques de fusta per al comerç interior i en altres contenidors destinats al comerç exterior marítim.

En moltes ocasions, els forns ubicats a l'interior devien la seva localització a la presència de villes. Les villes eren finques agràries independents formades per una edificació d'una sola planta amb un pati interior que unia les diferents habitacions de la casa i que estaven envoltades de camps de conreus, hortes, fruiters, jardins i boscos. Algunes d'aquestes vil- 
les es van especialitzar en el cultiu de la vinya i la producció de vi. A més, al seu voltant hi havia aigua, sòls argilosos i llenya, materials tots ells necessaris per a la ubicació d'un forn on s'elaboressin àmfores.

\section{Mapa 2 \\ Localització dels forns i ports en època romana}

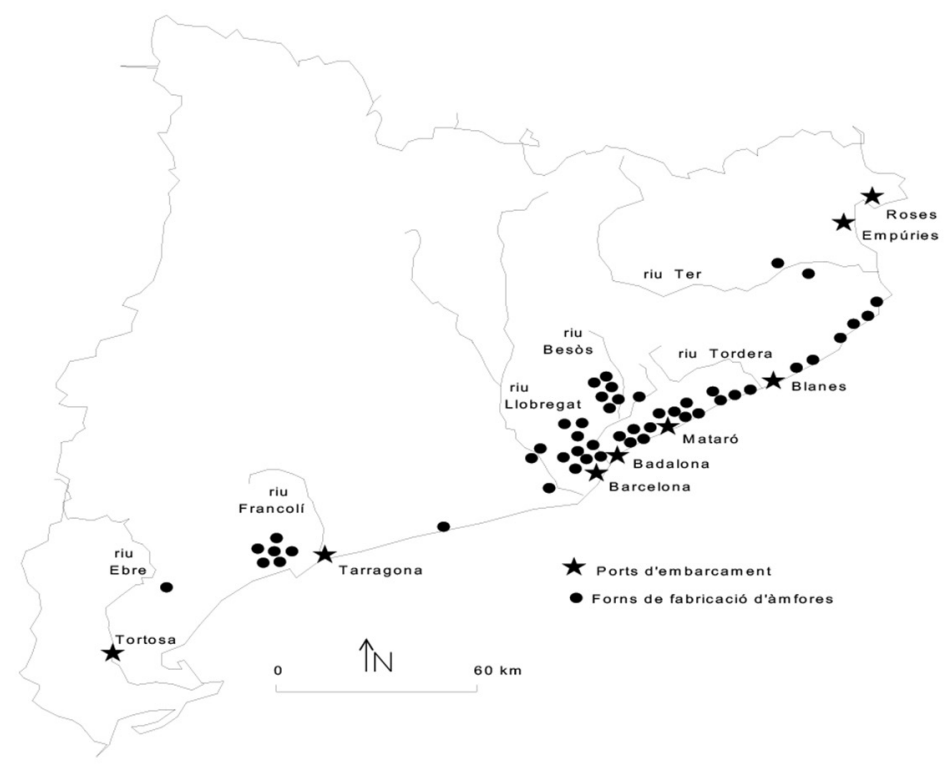

Font: Miró, J., 1988. Elaboració pròpia

D'aquesta manera, es pot establir que el cultiu de la vinya es trobava a les villes de l'interior i els voltants de les ciutats. Els forns de fabricació d'àmfores se situaven en aquests punts per recollir, de manera ràpida i directa, el vi que s'havia de transportar a les ciutats, a llocs de consumició o d'embarcament.

En el mapa 2 s'observen els ports d'embarcament, que de nord a sud eren: Roses, Empúries, Blanes, Mataró, Badalona, Barcelona, Tarragona i Tortosa, és a dir, que es cobria tot el litoral català, cosa que indica que el cultiu de la vinya es feia en tota la primera franja costanera catalana. També es percep una concentració a la part central -entre els rius Llobregat i Tordera-, i el Camp de Tarragona.

Si fem una comparació entre els mapes 1 i 2 , descobrirem que les DO catalanes del litoral probablement tenen un origen com a mínim romà: DO Empordà, DO Alella, DO Penedès i DO Tarragona. Però també les regions prelitorals banyades pels rius: DO Pla de Bages, DO. Montsant, DO Conca de Barberà i també DO Costers del Segre aprofitant els rius Ebre i Segre. 


\section{Els signes distintius de les DO que recullen els orígens vitivinícoles de l'edat antiga a Catalunya}

Aquest període històric el trobaríem recollit en el signe distintiu d'algunes de les denominacions d'origen que li donen valor com a marca comercial. Són el cas de la DO Penedès, DO Empordà i DO Tarragona, i cadascuna d'elles per a un dels tres períodes: iber, grec i romà.

\section{A) DO Penedès}

La DO Penedès ha canviat recentment el disseny del seu signe distintiu. S'hi veu el bust d'una deessa a sobre de la qual es fa constar el nom i els anys d'història de la vitivinicultura en aquesta regió barcelonina d'interior.

El Consell Regulador ens ha indicat que la marca figurativa es basa en un peveter trobat de la deessa grega de l'agricultura Demèter a les excavacions de la Font de la Canya (López, 2015). Al jaciment arqueològic d'aquesta població ibera, en la qual s'haurien establert relacions amb els fenicis i els grecs, es van trobar sitges amb pinyols de raïm carbonitzats datats del segle vir aC. Per tant, es considera que fa 2.700 anys que es practica la vitivinicultura en la regió del Penedès.

\section{Taula 1}

\section{Fitxa de presentació de la DO Penedès}

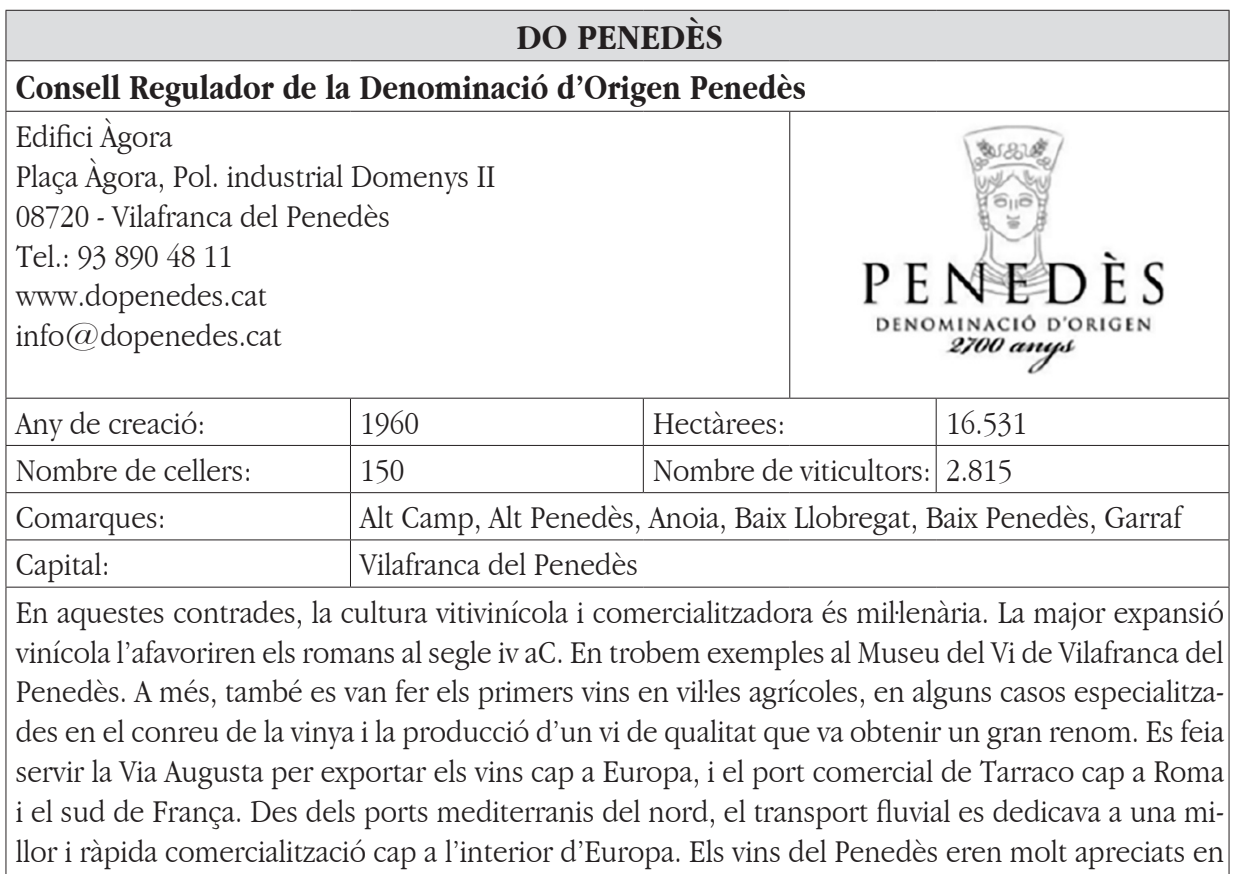


aquells moments, però també ho van ser als segles xviii i xix, quan van esdevenir el referent vi-
nícola de Catalunya amb l'extensió de vinyes més grans, la major producció i la major projecció
internacional, aprofitant el comerç vers Amèrica amb ports andalusos que tenien la primícia
d'exportació i la posterior arribada de la filloxera a França. Amb la filloxera es van produir canvis
innovadors que van fer canviar el paisatge d'aquesta regió. Avui dia té un gran reconeixement in-
ternacional.

Font: Pàgines web INCAVI i DO Penedès

En aquest cas, la DO vol potenciar el seu origen històric, ja que ha triat destacar en el disseny la imatge d'una de les primeres cultures relacionades amb la comarca i amb la vitivinicultura: la grega, la qual va entrar en contacte amb la població ibera ubicada a la zona compartint i intercanviant creences, productes i maneres de fer. I que, per tant, el que mostra és el valor ancestral en el conreu de la vinya i la producció de vi en aquestes contrades.

\section{B) DO Empordà}

El dibuix del logotip està format per un vaixell dels antics mariners grecs - amb una forma rodona i vela quadrada amb un sol pal-, fent referència a l'arribada a l'Empordà dels grecs per la mar Mediterrània i, per tant, de l'arribada del conreu de la vinya i la producció de vi en aquesta regió.

Taula 2

Fitxa de presentació de la DO Empordà

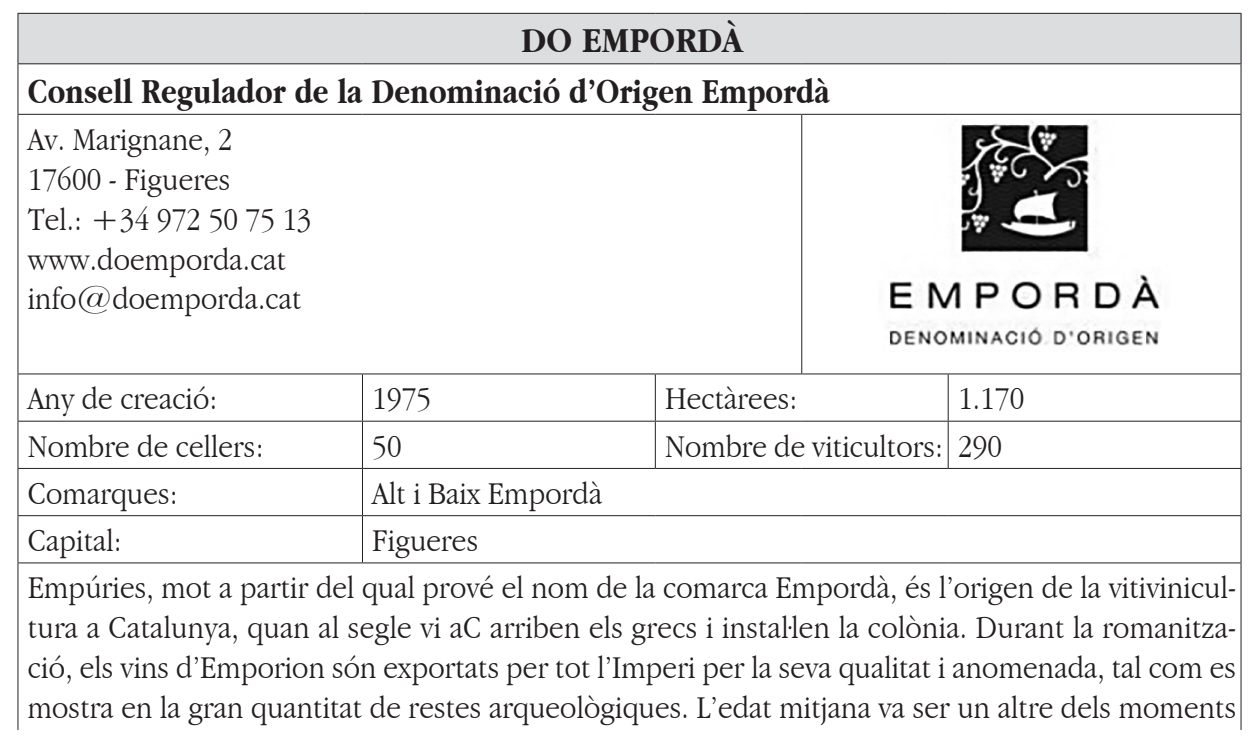


àlgids vitivinícoles de la regió, amb l'arribada i la installació dels monjos francesos als monestirs i,
posteriorment, durant el comerç amb Amèrica i l'arribada de la filloxera a França. El cooperativisme
va permetre la pervivència del sector després de la filloxera, la cerca de la producció d'un vi de
qualitat a partir de les noves plantacions als llocs òptims i la creació i l'expansió de la DO per tota
la regió empordanesa.

Font: Pàgines web INCAVI i DO Empordà

El Consell Regulador ens indicà que el disseny del segell estava inspirat en el relat mitològic grec del rapte de Dionís que es troba representat en unes rajoles de la cooperativa de Mollet de Peralada. Per bé que n'hi ha diverses versions, en una s'explica que Dionís, divinitat grega del conreu de la vinya i la producció i el consum de vi, va ser segrestat en un viatge marítim i, en resposta, ell va convertir els pals i les veles del vaixell en parres amb pàmpols i va transformar els pirates en dofins, que es van llançar al mar i fugiren.

En aquest cas, no només es fa referència històrica a l'arribada dels grecs a la regió, que van portar el conreu de la vinya i l'elaboració de vi, sinó també a la seva cultura i mitologia. És una manera de fer palesa, com s'ha vist en el cas anterior del Penedès, la presència de la vitivinicultura des de fa segles en aquestes terres i per tant, que el coneixement que és té del sector acumula molts anys d'història. També és una manera d'emfatitzar que en aquest territori es continua fent vi, salvant les situacions o els cicles que s'hi hagin viscut.

C) DO Tarragona

A partir de la informació aportada pel Consell Regulador de la DO Tarragona, se'ns ha confirmat que el logotip recull de tres maneres diferents l'origen millenari i romà de la vitivinicultura en la regió tarragonina: l'àmfora, les onades de l'àmfora i els colors. Com s'ha constatat anteriorment, l'àmfora era el recipient que permetia transportar el vi de qualitat a Roma des de les diferents regions productores de l'Imperi. Tarraco era la capital i el centre polític d'una extensa província d'Hispània, i port comercial de primer ordre, des d'on sortien vaixells cap a Roma amb els productes de qualitat més significatius d'aquestes terres. Però també n'hi havia que anaven cap a Gàllia, Germània i Britània, aprofitant una de les vies romanes més importants, la Via Augusta —actualment l'A-7- a més dels ports francesos enfilant cap al interior a través del transport fluvial del Roine cap al Danubi i el Rin. Ja hem assenyalat anteriorment que es feia constar als vins la procedència geogràfica de la Tarraconense mitjançant els segells, els precursors dels logotips actuals de la DO, tal com ho demostren els escrits dels autors llatins Sili Itàlic, Marcial i Plini. 
Taula 3

Fitxa de presentació de la DO Tarragona

\begin{tabular}{|c|c|c|c|}
\hline \multicolumn{4}{|c|}{ DO TARRAGONA } \\
\hline \multicolumn{4}{|c|}{ Consell Regulador de la Denominació d'Origen Tarragona } \\
\hline \multicolumn{3}{|c|}{$\begin{array}{l}\text { Carrer de la Cort, } 41 \\
43800 \text { Valls } \\
\text { Tel: } 977217931 \\
\text { www.dotarragona.cat } \\
\text { info@dotarragona.cat }\end{array}$} & 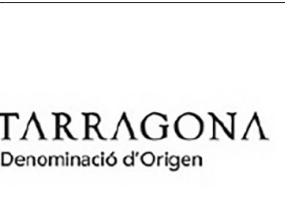 \\
\hline Any de creació: & (1947) 1976 & Hectàrees: & 4.560 \\
\hline Nombre de cellers: & 52 & Nombre de viticultors: & 1.367 \\
\hline Comarques: & \multicolumn{3}{|c|}{ Alt Camp, Baix Camp, Tarragonès i Ribera d'Ebre } \\
\hline Capital: & \multicolumn{3}{|c|}{ Tarragona } \\
\hline \multicolumn{4}{|c|}{$\begin{array}{l}\text { La vitivinicultura hi va arribar el } 218 \text { aC amb les tropes militars romanes que van convertir Tarraco } \\
\text { en un port militar i posteriorment en una gran ciutat comercial. Es va impulsar la producció vi- } \\
\text { nícola a les comarques del Camp de Tarragona i s'enviaven àmfores carregades de vi cap a Roma, } \\
\text { a la Gàllia, Germània o Britània, usant els ports i les vies fluvials. Durant l'edat mitjana fou molt } \\
\text { important el paper desenvolupat pels monestirs d'ordes francesos. Posteriorment, amb l'expansió } \\
\text { cap a Amèrica, aparegué un gran comerç de vins i aiguardents. La creació de la DO permet impul- } \\
\text { sar una gran varietat de vins, dels blancs als licors. }\end{array}$} \\
\hline
\end{tabular}

Font: Pàgines web INCAVI i DO Tarragona

En segon lloc, les onades que hi ha a l'àmfora fan referència a la influència directa de la Mediterrània en les vinyes i el vi de la DO Tarragona. Les vinyes es veuen afavorides pels aires provinents de la mar, que permeten reduir la temperatura deguda a l'alta insolació i augmentar la humitat durant els matins calorosos de l'estiu. Les vinyes de la denominació s'estenen del mar a l'interior, amb suaus ondulacions i entre els marges dels rius i rieres, alguns dels quals desemboquen a l'Ebre.

I, finalment, els colors que apareixen al logo mostren els colors dels vins que es poden produir a la regió, com ara els vins negres (antigament anomenats vermells), blancs, rosats i de licor.

\section{L'edat mitjana: els ordes monàstics francesos i l'orde del Temple}

Amb la caiguda de l'Imperi romà, la vitivinicultura a Catalunya havia tingut el seu primer declivi i no va ser fins a l'edat mitjana, amb l'arribada de monjos de diferents parts d'Europa, alguns d'ells d'ordes monàstics francesos — que s'installen als monestirs i conreen vi- 
nyes-, que no torna a ressorgir amb força la producció de vi (Martínez, 1991). En aquest aspecte destaquen els monestirs de Sant Pere de Rodes, Sant Cugat de Vallès, Santes Creus, Santa Maria de Poblet, Montserrat i la Cartoixa de Santa Maria d'Escaladei (Rexach, 2000), entre d'altres. A més, la ubicació de fortaleses, algunes de les quals pertanyents als membres de l'orde del Temple, ajudaren a la cultura de la vinya per a la producció de vi, com en el cas de Castelló d'Empúries (DO Empordà), Vallfogona i Barberà (ambdues DO Conca de Barberà), Joncosa (DO Penedès) i Castell de Miravet (DO Tarragona).

Segons Ferran Garcia-Oliver (2004), l'expansió vitivinícola a Catalunya durant els segles ix i x va ser deguda, especialment, a la cristianització de la societat —que va atorgar al vi un valor sacre-, a la captació de les rendes per part dels feudals, a les tradicions gastronòmiques i a la demanda urbana i mercantil. L'edat mitjana, entre els segles Ix i el xv, va marcar unes característiques vitivinícoles noves i en contínua evolució.

La població i els monjos que arribaven del sud de França i del nord de Catalunya i que s'installlaven en les noves terres conquerides van ser els actors que van començar a plantar vinyes i a produir vi. El vi es va convertir en un element essencial per a la societat catalana, ja que no tan sols estava present en les esglésies i en les cerimònies, sinó també a la taula diària. El vi oferia més valor nutritiu que l'aigua, que era més higiénica i saludable. A més, es va convertir, quan hi havia excedent, en un bon producte comercial.

El procés de colonització i d'un major ús de terra va comportar l'expansió de la viticultura, però a costa dels boscos i d'àrees marginals i no a costa de la superfície dedicada a altres cultius. La vinya ha estat una planta que es pot situar en els sòls no aprofitables per altres cultius, com en difícils vessants i serres abruptes, mitjançant la construcció de terrasses. Les vinyes oferien valor a un sòl que d'altra manera hauria resultat erm i sense valor (Ciurana, 1980). Així, es pot dir que la vinya es va fer present a tot el territori català, des de les zones més muntanyoses del nord fins a les planes del sud, aprofitant tant àrees suburbanes com bancals i àrees ermes (Vilà, 1973).

De la mateixa manera, el vi aportava uns ingressos econòmics extres als agricultors, i quan les vinyes excedien el consum familiar era venut a les tavernes de les grans poblacions. Va començar a iniciar-se, doncs, un comerç entre regions vinícoles productores i regions vinícoles consumidores (Freixas, 1966), que posteriorment es va estendre entre les urbs de la conca mediterrània.

\section{Els monestirs impulsen el sector vitivinícola durant l'edat mitjana}

Va ser fonamental per a l'augment de la superfície de la vinya el paper predominant que anaven adquirint els monestirs, alguns d'ells d'ordes religiosos francesos, que es van anar situant en els millors llocs del territori per a la pràctica de la vitivinicultura, tal com es pot observar en el mapa 3. Els religiosos necessitaven vi per a la celebració eucarística diària, i ells mateixos van començar a produir-ne. A més, eren persones erudites que van aplicar els coneixements vitivinícoles adquirits en els seus llocs d'origen en les noves terres que conreaven. Les relacions amb els monestirs francesos van continuar amb els segles i fins i tot 
es van intensificar amb el pelegrinatge a Santiago de Compostella a partir de l'any $897 \mathrm{dC}$, que va atreure pelegrins de tot Europa (Huetz, 2009). Aquestes relacions eren de tipus comercial, però també d'intercanvi de coneixements culturals i econòmics.

\section{Mapa 3 \\ Monestirs més importants en DO vitivinícoles catalanes}

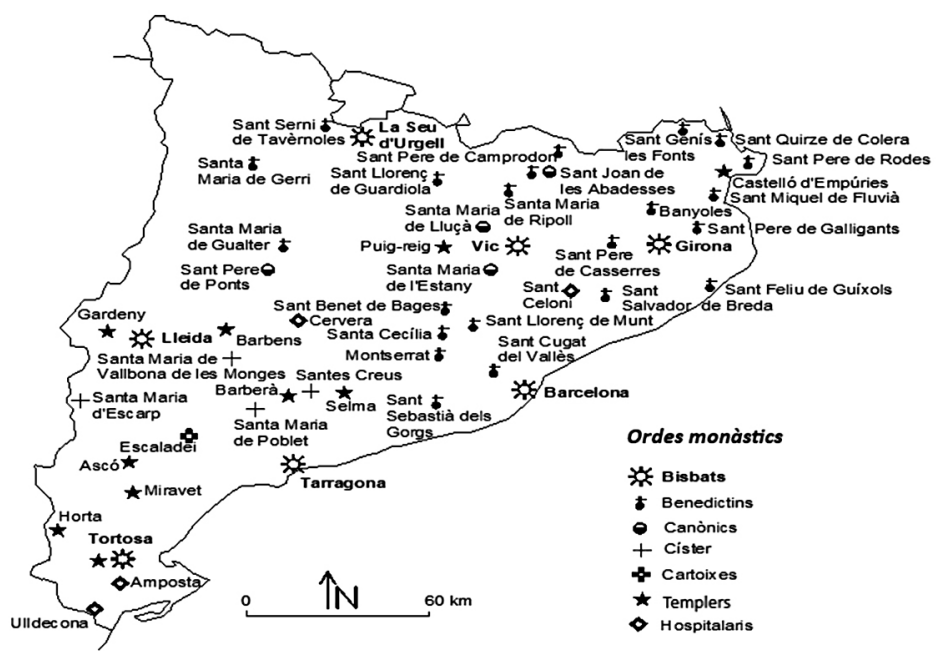

Font: Solà, A.; Farré, A., 1979, V, 146. Elaboració pròpia.

Els monestirs que es van ubicar a Catalunya van ser molt puixants: Santa Maria d'Escaladei, Santa Maria de Poblet, Vallbona de les Monges o Sant Benet de Bages. Les seves aportacions vitivinícoles van ser fonamentals perquè disposaven d'amplis coneixements sobre les diferents varietats vitícoles i les noves tècniques de vinificació. De fet, allà on es va situar un monestir hi ha actualment denominacions d'origen vitivinícoles (Martínez, 1991). Alguns exemples són el monestir de Sant Pere de Rodes, que ha donat lloc a la DO Empordà; el monestir de Sant Benet de Bages, que ha permès l'existència de la DO Pla de Bages; el monestir de Santa Maria de Poblet, que ha originat la DO Conca de Barberà i la cartoixa de Santa Maria d'Escaladei, que ha donat lloc a la DO Qualificada Priorat.

Els ordes monacals es basaven en lleis severes que prohibien molts aliments o l'excés de menjar, però toleraven el consum del vi. L'obtenció del vi significava per als monjos el favor de Déu i la seva manca el càstig diví. El vi era el símbol que representava la sang de Crist i la vida; per tant, els monjos consideraven que beure vi no podia ser pecaminós i que a la taula diària era el millor company del pa, símbol del cos de Crist.

L'arribada dels monestirs va ocasionar transformacions en l'agricultura en general i en la vitivinicultura en particular (Huetz, 2009; Martínez, 1991). En primer lloc, com que el treball dels monjos es basava en la pregària, obtenien els aliments de dues maneres: mitjan- 
çant l'explotació directa o l'explotació indirecta (Bonnassie, 1979). En el primer cas, alguns «monjos conversos» realitzaven les activitats agràries, ja que eren grangers que a causa de l'augment demogràfic dels primers segles de l'edat mitjana no tenien altre sistema de subsistència que el d'entrar a formar part dels monestirs com a germans. En el segon cas, quan la població monacal era més reduïda o no existien aquests «monjos conversos», era quan es recorria a l'explotació indirecta: els camperols treballaven la terra i lliuraven una part de la collita o pagaven unes rendes als monjos, els quals eren els propietaris de les terres.

La segona aportació dels monestirs va ser la implantació del cultiu de les lleguminoses i la introducció de noves tècniques agrícoles. Els monjos consumien cereals -blat, sègol, e mill o ordi-, però com a proteïnes van substituir la carn per lleguminoses. La introducció de les lleguminoses en la dieta dels monjos va repercutir en el sistema de cultiu. Fins llavors s'havia dividit el camp en tres parts: la dels cereals, la de pastures i la que es deixava en guaret. Quan s'introdueixen les lleguminoses, ja no cal deixar la terra en guaret, ja que aquestes regeneren el sòl i augmenten la superfície conreada i la producció. Així mateix, les lleguminoses servien d'aliment a les persones, fins i tot un cop seques; les plantes es donaven als animals i el cultiu servia de fertilitzant per al sòl. En millores tècniques, destaca la substitució dels aparells de fusta pels de ferro (Bonnassie, 1979; Furió, 2004), el reemplaçament de l'arada romana que només esgarrapava el sòl per l'arada de pala, que removia completament la terra, i el canvi dels bous per les mules perquè eren més ràpides.

Un tercer aspecte fa referència a l'apartat comercial, en el qual els monestirs comencen a prendre part en la producció d'excedents, especialment de llana i vi. Els monestirs es van convertir en grans centres comercials i d'intercanvi i alguns van arribar a fer grans fortunes (Freixas, 1966; Martínez, 1991). Hi havia les aportacions dels creients, en diners o terres, els excedents agraris a causa de les millores esmentades anteriorment i les rendes. És cert que alguns productes havien d'obtenir-los fora del monestir, però tot $i$ així la riquesa obtinguda era superior a la despesa.

El 1836, la desamortització de Mendizábal va suposar la venda de les terres i de les propietats dels ordes religiosos. Les vinyes van passar a mans dels nobles que van comprar les terres, però no va succeir el mateix amb els coneixements que els monjos tenien sobre la vitivinicultura. A. Martínez (1991) recull la idea que la sacralització d'aquelles terres vitivinícoles després de la desamortització va ser la responsable de la maledicció de la filloxera de finals del segle xix.

\section{L'orde del Temple $i$ el seu establiment en castells $i$ comandes}

L'orde del Temple estava format per monjos soldats, és a dir, cavallers que, havent fet vots monàstics i vivint en comunitat, consagraven la seva vida a la defensa dels peregrins que viatjaven a Terra Santa i a la protecció dels Sants Llocs. Els seus membres seguien regles de pregària, de treball i de preparació militar.

Quan al segle xiI van arribar a la península Ibèrica, els cavallers templers van començar a fer un paper semblant al dels senyors feudals, fomentant la repoblació, els drets de con- 
reu i l'establiment en castells i fortaleses. A la Corona d'Aragó, aviat van ser reconeguts i afavorits per la Cort i els comtats, que cercaven la seva protecció amb donacions econòmiques, edificacions i dominis territorials agraris, anomenats comandes. De fet, cada comanda disposava de terres agràries i d'un espai residencial, productiu, amb magatzems i església o capella. La feina dels templers consistia a explotar aquests béns (conreus, ramats, boscos), a més exercir justícia. Alhora, hi havia membres que s'installlaven a ciutat, i en aquest cas gestionaven els diners fent de banquers, oferint préstecs i acceptant dipòsits.

L'orde del Temple la trobem en especial a la Catalunya Nova, per sota del riu Llobregat, per bé que també n'hi ha comandes al nord. Així tindríem les de Castelló d'Empúries, Aiguaviva, Puig-reig, Palau-solità, Palau (a la ciutat de Barcelona), Joncosa, Gardeny, Barbens, Granyena, Vallfogona, Barberà, Riba-roja, Ascó, Miravet, Horta i Tortosa.

\section{La marca significativa de les DO vinculada amb l'edat mitjana}

Encara avui, trobem vinyes que envolten els monestirs i els castells interiors de Catalunya, alguns dels quals segueixen actius, però la majoria estan abandonats o se'n fa un nou ús. Cal destacar els monestirs que formen la ruta del Cister (Santes Creus, Poblet i Vallbona de les Monges), la Cartoixa d'Escaladei i els castells medievals de la Conca de Barberà, on trobem les DOQ Priorat, DO Montsant i DO Conca de Barberà que fan servir una imatge al seu segell que recorda aquest període històric de l'edat mitjana. A més, la DO Catalunya és representada pel seu símbol més emblemàtic, present tant a la senyera com a l'escut de Catalunya: les quatre barres, record històric del moment culminant en el qual Catalunya neix com a «terra de castells».

\section{A) DOQ Priorat}

La imatge del logotip de la DOQ Priorat, l'única Denominació d'Origen Qualificada de Catalunya, representa una escala que va cap a Déu (la creu), amb un àngel a cada banda dels quals es desprenen uns rä̈ms.

La Cartoixa d'Escaladei està ubicada al Priorat, sota la serra del Montsant. Els monjos que hi arribaren a l'edat mitjana procedents de França buscaven un lloc per ubicar-se que fos tranquil, apte per al conreu i allunyat del món per poder dedicar-se a la contemplació de Déu. Sentiren parlar un pastor sobre un somni que va tenir en aquell lloc: veia una escala que anava cap al cel, d'on baixaven i pujaven els àngels. I s'hi van installar el 1194. Amb el temps, la Cartoixa va guanyar molt protagonisme i riquesa, i els seus vins eren molt reconeguts a tot Europa, de manera que el seu prior va donar nom a la comarca.

El signe distintiu de la DO valora amb aquesta imatge l'origen no només del vi de qualitat, sinó també de la comarca. Al Priorat s'hi fa vi amb l'arribada dels monjos, que construïren allà el seu monestir, plantaren les vinyes i prodüren vi per al seu consum, encara que a la llarga van utilitzar aquest producte com a bé comercial. Va tenir molta anomenada i, tot i que va viure un període d'ostracisme molt llarg, ha ressorgit amb força. És significatiu que actualment el disseny de la seva marca comercial destaqui l'origen de la comarca i de l'elaboració del vi, emfatitzant la religiositat. 
Taula 4.

Fitxa de presentació de la DOQ Priorat

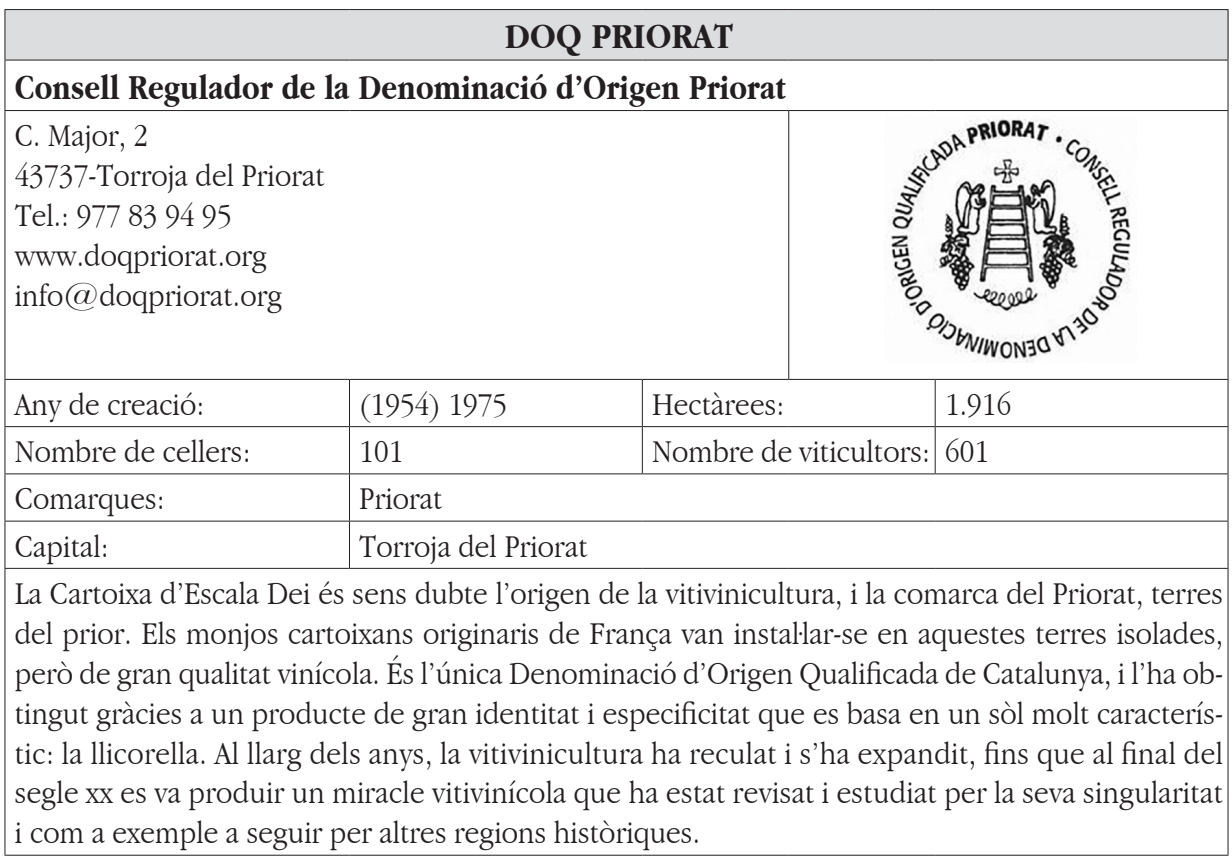

Font: Pàgines web INCAVI i DOQ Priorat

B) DO Montsant

El Consell Regulador ens explica que la DO aglutina 17 municipis, majoritàriament de la comarca del Priorat i alguns de la Ribera d'Ebre. El nom de la DO procedeix del de la serralada en forma de ferradura del Montsant, que es contempla des de qualsevol dels pobles que en formen part, i que envolta completament la zona de la DOQ Priorat.

Taula 5.

Fitxa de presentació de la DO Montsant

\begin{tabular}{|l|l|l|}
\hline \multicolumn{3}{|c|}{ DO MONTSANT } \\
\hline Consell Regulador de la Denominació d'Origen Montsant \\
\hline Pl. Quartera, 6 & \\
43730 Falset & \\
Tel.: 977831742 & \\
Fax: 977830676 & Hectàrees: & 1.850 \\
www.domontsant.com & 2001 & D \\
\hline Any de creació: &
\end{tabular}




\begin{tabular}{|l|l|l|l|}
\hline Nombre de cellers: & 69 & Nombre de viticultors: & 750 \\
\hline Comarques: & Priorat i Ribera d'Ebre \\
\hline Capital: & Falset & L'origen de la producció de vi en aquest territori prové de l'Imperi romà, com ho testifiquen les \\
restes d'un assentament romà a Marçà amb àmfores vinícoles que s'exportaven cap al mercat de \\
Tarraco. Els monjos cartoixans d'Escaladei impulsaren el sector i la comercialització dels vins de la \\
regió durant l'edat mitjana, com passà amb la DOQ Priorat, però la zona del Montsant estava més \\
oberta i era d'accés més fàcil, afavorit per la presència dels castells. Montsant va utilitzar la ciutat \\
de Reus i el port de Salou durant l'expansió cap a Amèrica i, posteriorment, el cooperativisme i \\
l'aparició del ferrocarril cap a l'interior durant el segle xx. Durant molt de temps va estar vinculada \\
amb la DO Tarragona, fins que per la seva especificitat i singularitat va ser capaç de crear una \\
DO pròpia.
\end{tabular}

Font: Pàgines web INCAVI i DO Montsant

El logotip, amb uns vint anys d'història, està format pel nom de la DO: Montsant, destacant-s'hi en color granat la lletra «t» que quasi s'hi troba al mig. El nom de la serra del Montsant ve de molt lluny, ja que ha estat considerada una muntanya santa i espiritual, fins i tot màgica, no només pel cristianisme, sinó també per altres creences místiques, religioses i espirituals. Com s'ha comentat, als peus d'aquesta serra es va fundar la Cartoixa d'Escaladei i amb el temps ha donat lloc al nom de la comarca del Priorat, és a dir, terra del prior. Així doncs, el logotip fa referència a la forma de la serra usant el nom de Montsant, a l'espiritualitat que ha transmès aquesta muntanya al llarg de la història i que es vincula en especial a la presència als peus de la muntanya de la Cartoixa d'Escaladei, d'aquí la creu destacada i en consonància amb la lletra «t», de Montsant. A més, la lletra destaca pels colors, així la paraula té els colors marrons de la muntanya i la «t» el color grana del vi que s'hi fa.

S'ha de tenir en compte en aquest cas que Montsant era una de les subzones més importants de la DO Tarragona. Es diferencia de la DOQ Priorat en el tipus de sòl, més argilós i sense presència de llicorella. Quan va esdevenir una DO amb entitat pròpia va ressaltar la seva multiculturalitat: s'hi fan vins de qualitat, però també, fora pròpiament de la regió qualificada, es produeixen vins caixer per a la comunitat jueva d'Israel i vins de missa per a la ciutat del Vaticà. L'origen de la producció vitivinícola d'aquesta DO la trobem durant el període romà i la seva expansió va tenir lloc durant la comercialització de licors i aiguardents cap a Amèrica a través del port de Reus. El fet d'introduir aquesta DO dins l'apartat de l'edat mitjana es deu a la presència en el disseny del segell de la DO de la serra del Montsant que envolta la Cartoixa d'Escaladei i que emfatitza la creu amb la «t», per tant, destaca la religiositat que es va produir especialment durant aquest període. En aquella època, convisqueren juntes les tres religions monoteistes: el cristianisme, el judaisme i l'islam.

C) DO Conca de Barberà

Realment és un logotip molt peculiar i original. El Consell Regulador ens ha informat que la marca d'identitat de la DO Conca de Barberà simbolitza un segell templer. 
Un segell d'una matriu de bronze (que es feia servir per lacrar cartes), dels pocs exemplars que en queden i que pertanyia a l'orde templer de Sant Joan de Jerusalem, va ser regalat al president de la DO. Com s'ha comentat abans, tant els monestirs com l'orde del Temple van ser molt importants per a la difusió de la producció vinícola de la Catalunya medieval. Hi ha el text: «Preceptoria Barberana» (vinculat amb el nom de la DO, de la comanda templera Barberà) i un peix dibuixat. La dita popular afirma que el nom de Barberà ve del peix barb, i d'aquí el nom i la presència dels peixos en l'escut del municipi. S'ha de pensar que el peix simbolitzava Jesucrist i que moltes vegades els primers cristians es reconeixien dibuixant un peix a terra. Això prové del grec (que vol dir 'peix'), ja que l'acròstic (cada una de les inicials) d'aquesta paraula significa «Jesús fill de Déu Salvador». També s'ha de tenir en compte que a Montblanc s'hi recrea la llegenda de Sant Jordi, d'origen medieval de forma anual.

Taula 6

Fitxa de presentació de la DO Conca de Barberà

\begin{tabular}{|c|c|c|c|}
\hline \multicolumn{4}{|c|}{ DO CONCA DE BARBERÀ } \\
\hline \multicolumn{4}{|c|}{ Consell Regulador de la Denominació d'Origen Conca de Barberà } \\
\hline \multicolumn{3}{|c|}{$\begin{array}{l}\text { Torre del Portal de Sant Antoni } \\
\text { c/ de la Volta, } 2 \\
43400 \text { - Montblanc } \\
\text { Tel.: } 977926905 \\
\text { www.doconcadebarbera.com } \\
\text { info@doconcadebarbera.com }\end{array}$} & 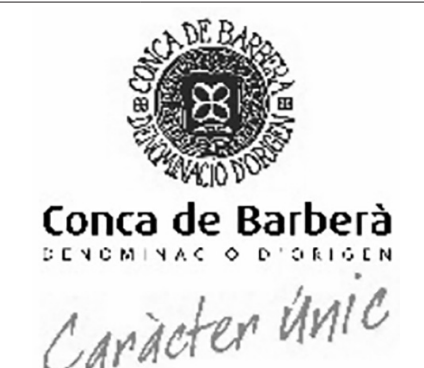 \\
\hline Any de creació: & 1989 & Hectàrees: & 3.500 \\
\hline Nombre de cellers: & 21 & Nombre de viticultors: & \\
\hline Comarques: & \multicolumn{3}{|c|}{ Conca de Barberà } \\
\hline Capital: & \multicolumn{3}{|c|}{ Montblanc } \\
\hline \multicolumn{4}{|c|}{$\begin{array}{l}\text { El conreu de la vinya i la producció de vins provenen dels romans, que feren valer el lloc com a } \\
\text { punt geogràfic estratègic cap a l'interior, el sud i el nord de la província romana Tarraconense. } \\
\text { La vitivinicultura de la Conca de Barberà té el seu moment àlgid durant l'edat mitjana, amb la } \\
\text { unió de l'orde dels monjos cistercencs de Santa Maria de Poblet i l'orde del Temple, establerts } \\
\text { tots dos a Barberà, provinents de França i que transmeten als pagesos tant els seus coneixements } \\
\text { per conrear la vinya com per produir vins de qualitat. Posteriorment, fou molt important el mo- } \\
\text { viment cooperativista per rellançar el sector després de la filloxera, la qual cosa permeté la creació } \\
\text { de la DO. }\end{array}$} \\
\hline
\end{tabular}

Font: Pàgines web INCAVI i DO Conca de Barberà 
D) DO Catalunya

És la DO més recent i engloba gran part del territori català. Aprofitant la «y», es fa servir com la quarta barra de l'escut i la senyera, tots dos símbols de Catalunya. El nom de la DO és de color daurat.

\section{Taula 7}

Fitxa de presentació de la DO Catalunya

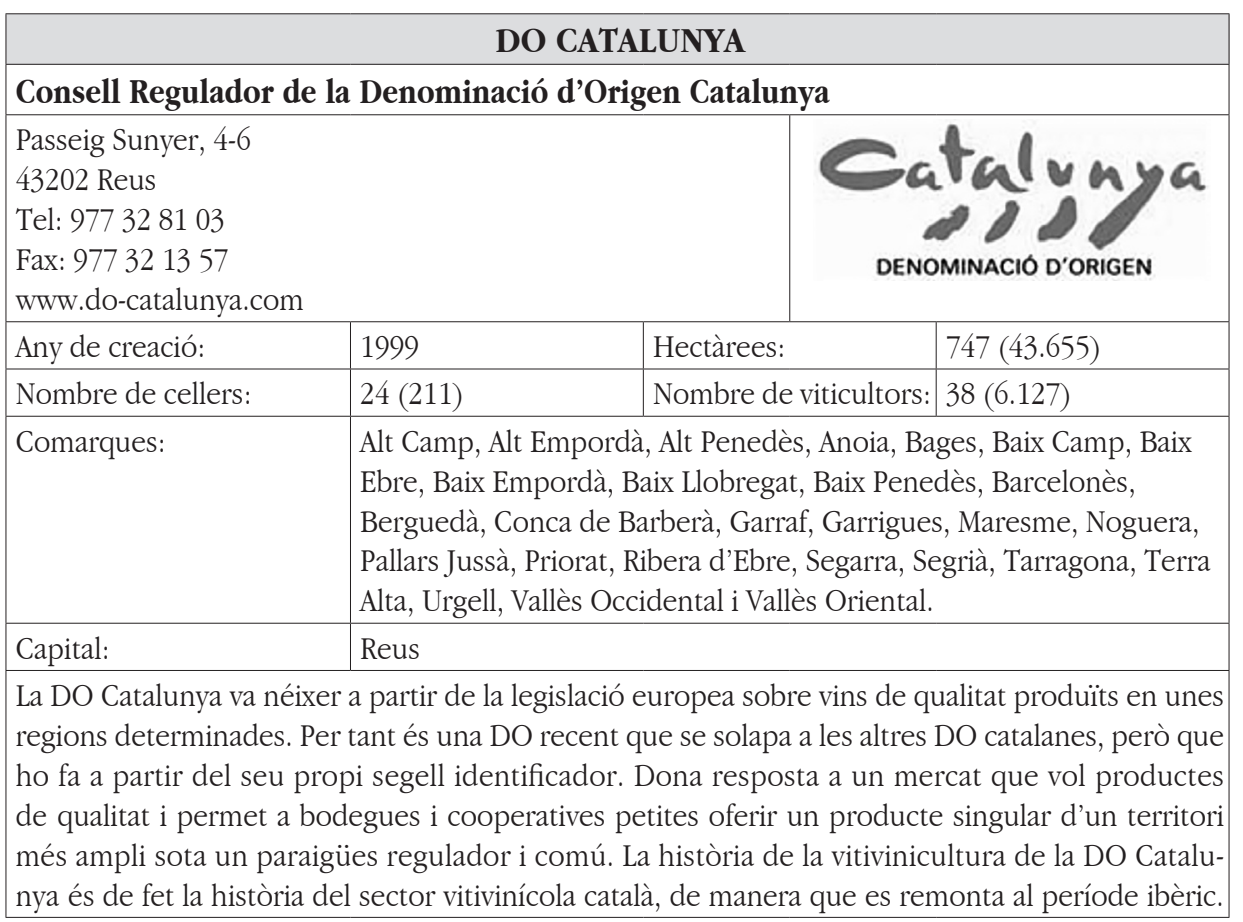

Font: Pàgines web INCAVI i DO Catalunya

Segons la llegenda, Guifré el Pelós, en el seu llit de mort, va dibuixar — amb els quatre dits de la mà i la seva sang- quatre barres al seu escut daurat. Potser d'aquí prové el color de les lletres de la DO. Ara bé, les quatre barres són documentades per primera vegada el 1150, en un segell emprat per Ramon Berenguer IV, com a símbol heràldic de la casa comtal de Barcelona. Per tant, ens trobem amb un motiu de cavallers feudals en què la marca d'identitat era molt important. El que és interesant és que l'escut que representava la casa comtal de Barcelona esdevingué a la llarga l'escut de Catalunya. Ramon Berenguer IV, a més, va tenir vincles diplomàtics amb l'orde del Temple i els va fer concessions i donacions.

En aquest cas, el disseny del signe d'identificació de la DO es basa en una qüestió patrimonial que té el seu origen al període medieval. És cert que la DO Catalunya va néixer 
— com s'indica en la fitxa-com a producte comercial per al mercat europeu, però si es valoren les zones compreses dins d'aquesta regió qualificada podria haver-se escollit qualsevol període històric anterior per emfatitzar la tradició vitivinícola catalana. Amb tot, el dibuix s'ha vinculat amb l'origen del nom de la DO, que alhora va ser un dels moments àlgids de la vitivinicultura a Catalunya.

\section{Els signes distintius de les DO catalanes sense vincle històric}

Hi ha tot un altre seguit de segells identificadors de les DO que no tenen referències històriques, i són els de la DO Alella, DO Costers del Segre, DO Pla de Bages i DO Terra Alta. Tenint en compte que les quatre regions tenen també una llarga història vitivinícola, i a més des del període grec i/o romà, és destacable que en aquest cas s'hagin usat altres motius per als dissenys dels logotips. Però justament és el que té una marca comercial, que pot estar basada en fets més subjectius no com la DO, que és una entitat regulada jurídicament i administrativament.

\section{A) DO Alella}

La DO Alella té com a logotip una doble «A» invertida, la primera simbolitzant un raïm daurat i la segona simbolitzant la inicial de la DO d'un color maragda (verd/blau).

El Consell Regulador ens ha informat que el símbol pretén ser modern i unitari. La «A» pot representar un raïm, però també la muntanya que llisca vers el mar i que està coberta de vinyes (d'aquí el color maragda, verd de les plantes i blau del mar). És una marca conceptual que busca força visual i que es pugui reconèixer fàcilment.

La DO, com s'indica a la fitxa, té una llarga tradició vitivinícola, però en aquest cas s'han emfatitzat més altres aspectes, donant a la marca una major vistositat i frescor, a més de naturalitat i sostenibilitat, per apropar-la al jovent. Recordem que l'elaboració de vins d'aquesta zona va estar a punt de desaparèixer a causa de l'urbanisme i el turisme, i que va ser la població de la comarca qui va salvar el sector vitivinícola.

\section{Taula 8}

\section{Fitxa de presentació de la DO Alella}

\begin{tabular}{|c|c|c|c|}
\hline & & ELLA & \\
\hline Consell Regula & Denominac & sen Alella & \\
\hline $\begin{array}{l}\text { Masia Museu Car } \\
\text { Av. Sant Mateu, } \\
08328 \text { - Alella } \\
\text { Tel.: } 93555915 \\
\text { www.doalella.or } \\
\text { dolallella@doal }\end{array}$ & & & \\
\hline Any de creació: & (1955) 1976 & Hectàrees: & 227 \\
\hline
\end{tabular}




\begin{tabular}{|l|l|l|l|}
\hline Nombre de cellers: & 9 & Nombre de viticultors: & 46 \\
\hline Comarques: & Maresme i Vallès Oriental \\
\hline Capital: & Alella \\
\hline A Alella s'hi fa vi des de l'època dels grecs, a més del gran impuls que reberen durant el període \\
romà, ja esmentats per Plini i Marcial com a vins laietans i exportats a Roma amb àmfores fetes a \\
Mataró. Durant l'edat mitjana, els vins d'Alella foren els preferits de la cort medieval barcelonina i \\
es consideraven vins de gust i amb anomenada. Van gaudir d'una gran expansió amb la comercia- \\
lització cap a Amèrica al segle xviii i, després de la filloxera, gràcies al cooperativisme, van tornar a \\
ser molt apreciats pels barcelonins, en especial, entre la burgesia i els polítics. La creació de la \\
DO ha permès en gran part la seva supervivència fins a l'actualitat.
\end{tabular}

Font: Pàgines web INCAVI i DO Allela

B) DO Costers del Segre

En aquest cas, el Consell Regulador ens indica que la DO Costers del Segre ha canviat recentment la seva imatge.

El disseny és semblant al de la DO Montsant, pel fet que també juguen amb el nom de la DO. En el cas de la DO Costers del Segre, el nom fa referència a les set subzones geogràfiques que formen part de la DO. És particularment curiós que també s'estableixi la lletra «t» com a símbol destacat de la regió, encara que en aquest cas és d'un color verd que el vol vincular amb les vinyes i amb l'ecologisme. Aquí, la «t» es transforma en «7» en referència a les set subzones.

Encara que la DO Costers del Segre és una indicació geogràfica relativament recent, comparada amb d'altres, també té una llarga història i una tradició vitivinícola des de períodes antics.

Taula 9

Fitxa de presentació de la DO Costers del Segre

\begin{tabular}{|c|c|c|c|}
\hline \multicolumn{4}{|c|}{ DO COSTERS DEL SEGRE } \\
\hline \multicolumn{4}{|c|}{ Consell Regulador de la Denominació d'Origen Costers del Segre } \\
\hline \multicolumn{2}{|c|}{$\begin{array}{l}\text { Complex de la Caparrella, } 97 \\
\text { 25192 Lleida } \\
\text { Tel.: } 973264583 \\
\text { Fax: } 973264583 \\
\text { www.costersdelsegre.es } \\
\text { secretari@costersdelsegre.es }\end{array}$} & & $\begin{array}{l}\text { OS7ERS } \\
\text { EL } \\
\text { ERRE } \\
\text { onominació } \\
\text { Origen }\end{array}$ \\
\hline Any de creació: & 1988 & Hectàrees: & 4.212 \\
\hline Nombre de cellers: & 44 & Nombre de viticultors: & 515 \\
\hline Comarques: & $\begin{array}{l}\text { Pallars } \\
\text { Garrig }\end{array}$ & $\begin{array}{l}\text { birà, el Segrià, l'Urgell, e } \\
\text { i la Segarra }\end{array}$ & Pla d'Urgell, les \\
\hline Capital: & Lleida & & \\
\hline
\end{tabular}


DO Costers del Segre té els primers vestigis durant la romanització. A l'edat mitjana s'hi van installar monestirs i castells. El cooperativisme agrari, el Canal Catalunya-Aragó i l'establiment de grans empreses productores i innovadores de vi han estat el revulsiu d'aquesta regió que es va consolidar amb la creació de la DO.

Font: Pàgines web INCAVI i DO Costers del Segre

El seu signe distintiu és del 2018, per tant, una denominació d'origen jove i amb la cultura pròpia actual vinculada amb la sostenibilitat i la natura.

C) DO Pla de Bages

El disseny del segell de la DO Pla de Bages és geogràfic i representa la forma de la comarca del Bages, de la DO i també la fulla de la vinya, un pàmpol. D'altra banda, juga amb els colors de la terra: marró i verd.

Com la DO Costers del Segre, la comarca té una tradició ancestral, ja de l'època romana. En alguns casos, es considera que el nom prové de Baco, el deu romà del vi, coronat amb pàmpols, fet que es podria relacionar amb la imatge del signe distintiu. Encara que el Bages també és conegut per les seves fonts d'aigua, algunes de curatives. No obstant, es fa més evident el valor geogràfic de la imatge que el d'una possible representació de l'època romana, i ha quedat relacionada amb la sostenibilitat i la natura.

Taula 10

Fitxa de presentació de la DO Pla de Bages

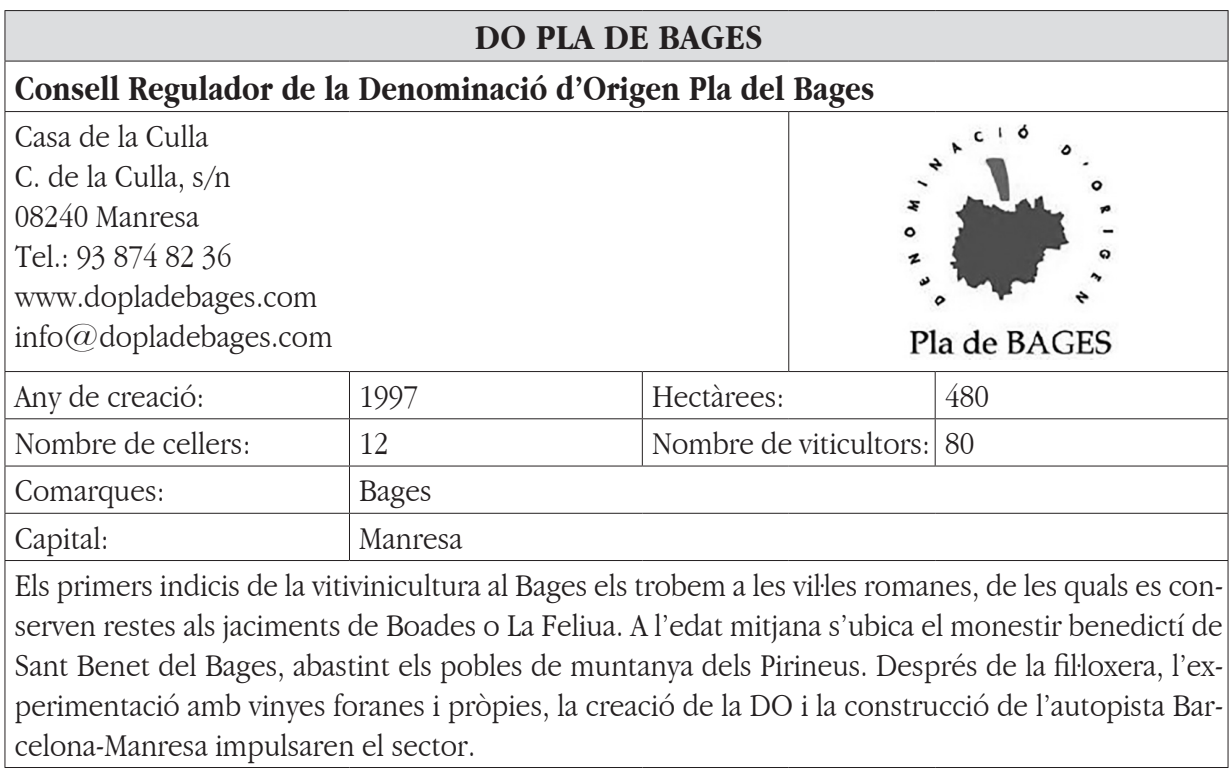

Font: Pàgines web INCAVI i DO Pla de Bages 
D) DO Terra Alta

La DO Terra Alta també fa ús de les paraules que formen part del nom de la Denominació d'Origen. En aquest cas, s'hi juga amb les inicials: per una banda la «T» de color roig i la «A» de color daurat.

També s'hi presta més al joc la inicial «A», com a la DO Alella. En aquest cas, representa un raïm invertit, simbolitzant també una muntanya en tractar-se d'una regió muntanyosa de l'interior de Catalunya. Els colors emprats són el terrós i el daurat representant el sòl, el raïm blanc propi del vi característic de la DO i el color de les terrasses i els turons.

També és una DO amb història vitivinícola ja des de l'edat mitjana. El nom de la comarca i per tant de la DO fa referència a un dels dominis importants de l'orde del Temple, però, com en els casos anteriors, tampoc no es veu reflectida la rellevància històrica en el disseny de la marca de la DO. S'ha donat èmfasi a aspectes més visuals i toponímics.

Taula 11

Fitxa de presentació de la DO Terra Alta

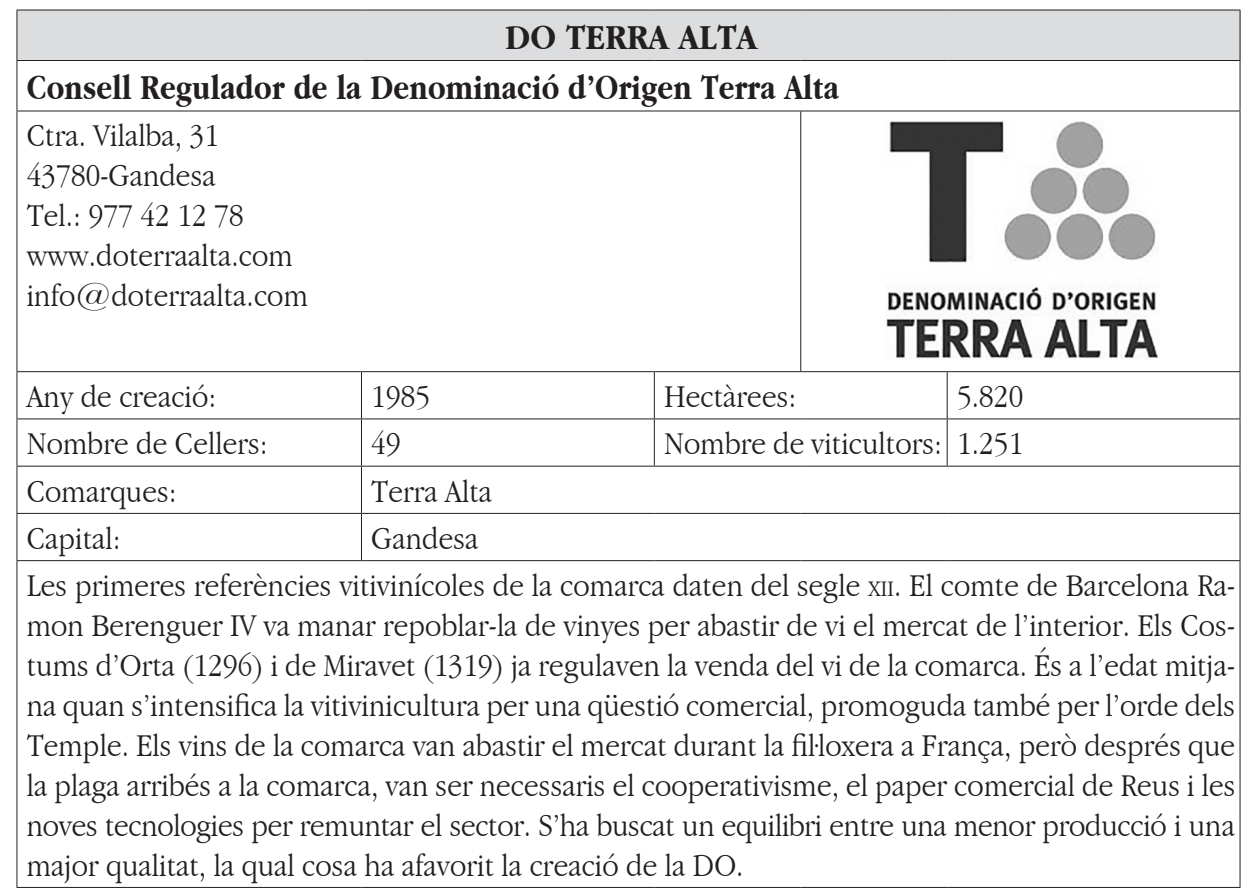

Font: Pàgines web INCAVI i DO Terra Alta 


\section{Conclusions}

De les 11 denominacions d'origen, 7 signes distintius tenen a veure - directament o indirectament-amb motius històrics, tal com es veu en la taula 12 . Fan referència a moments àlgids o de l'origen del conreu de la vinya per a la producció del vi i la comercialització posterior. S'ha d'entendre que, per a una DO, la història de la vitivinicultura és molt important, quasi tant com els aspectes geogràfics del sòl i el clima. Perquè justament mostren la seva importància al llarg dels segles i un testimoni que ha arribat fins als nostres dies.

\section{Mapa 4 \\ Ubicació de les DO vitivinícoles a Catalunya on s'indiquen els motius dels signes distintius per temàtica}

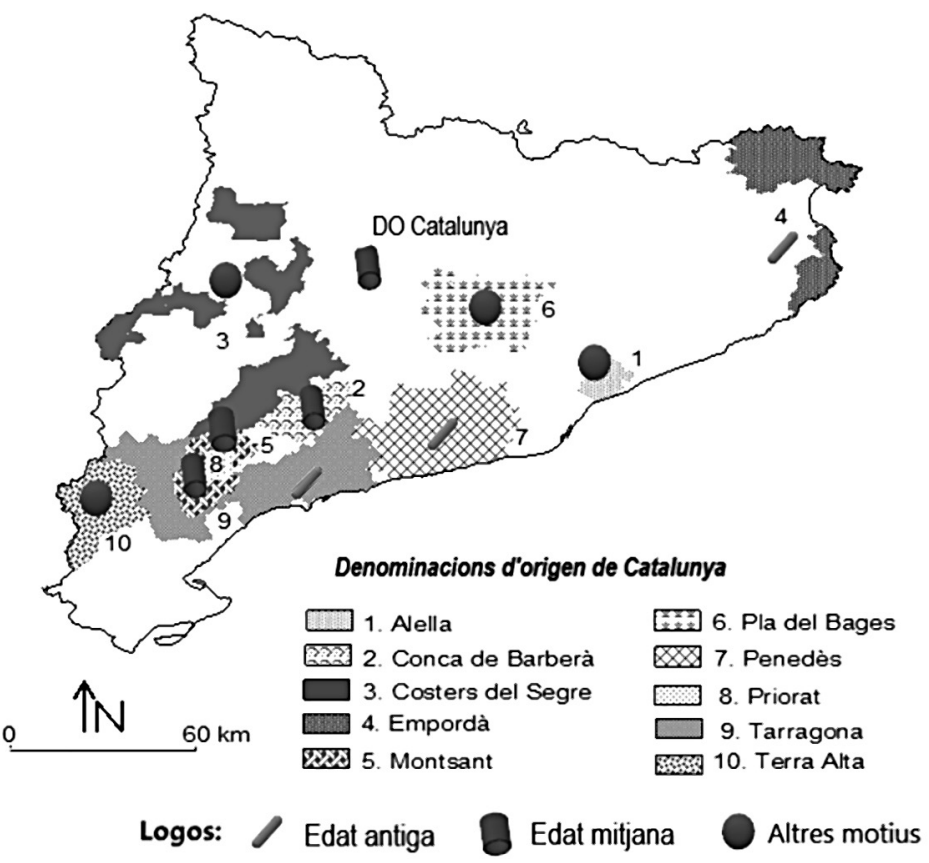

Font: Elaboració pròpia a partir de la informació aportada per aquest treball de recerca

I és per això que els dos moments més representats pels segells identificadors d'una DO catalana han estat els primers: l'edat antiga i l'edat mitjana, obviant altres períodes que igualment van ser molt representatius, com ara l'expansió de la producció de vi i aiguardent per enviar cap a Amèrica a l'edat moderna o l'arribada de la filloxera, que va suposar grans canvis en la plantació de vinyes ja a l'edat contemporània.

Així, els períodes històrics treballats s'han agrupat en dos: l'edat antiga amb els orígens vitivinícoles en el període ibèric i amb l'arribada de grecs i romans; i l'edat mitjana amb 
l'arribada dels monjos europeus i dels cavallers en un sistema feudal que permeté l'expansió vitivinícola a través dels monestirs i dels castells en gran part del territori català.

En el mapa 4, s'observa que els dissenys històrics es troben precisament en aquells períodes que ja s'havien assenyalat tant en l'edat antiga - denominacions d'origen litoralscom en l'edat mitjana - denominacions d'origen d'interior que haurien format part de la Catalunya Nova.

\section{Taula 12}

Motius de les imatges de les DO catalanes per temàtica

\begin{tabular}{|c|c|c|c|c|c|c|}
\hline \multirow[t]{3}{*}{ DO } & \multicolumn{5}{|c|}{ ORIGEN DEL LOGO DE LA DO } & \multirow[t]{3}{*}{ ALTRES } \\
\hline & \multicolumn{3}{|c|}{ EDAT ANTIGA } & \multicolumn{2}{|c|}{ EDAT MITJANA } & \\
\hline & Ibèria & Grècia & Roma & Monestirs & Castells & \\
\hline \multicolumn{7}{|l|}{ Alella } \\
\hline \multicolumn{7}{|l|}{ Catalunya } \\
\hline \multicolumn{7}{|l|}{ Conca de Barberà } \\
\hline \multicolumn{7}{|l|}{ Costers del Segre } \\
\hline \multicolumn{7}{|l|}{ Empordà } \\
\hline \multicolumn{7}{|l|}{ Montsant } \\
\hline \multicolumn{7}{|l|}{ Pla de Bages } \\
\hline Penedès & 8 & & & & & \\
\hline \multicolumn{7}{|l|}{ Priorat } \\
\hline \begin{tabular}{|l} 
Tarragona \\
\end{tabular} & & & 8 & & & \\
\hline \multicolumn{7}{|l|}{ Terra Alta } \\
\hline Total & & 3 & & & & 4 \\
\hline
\end{tabular}

Font: Elaboració pròpia a partir de la informació aportada per aquest treball de recerca

Per tant, no s'ha valorat que la DO fos creada en aquell període o la producció de vi tingués el seu origen en el període remarcat en el dibuix del signe distintiu de la DO, sinó que la imatge representada en la marca de la DO evoca un període històric concret de la vitivinicultura més o menys important en aquella zona. Es remarca aquest fet perquè hi ha DO que han triat un disseny que no recull fets històrics, no perquè siguin de nova creació, sinó perquè han decidit apostar per altres simbolismes — com ara la DO Terra Alta— i, alhora, n'hi ha que sí han recollit un fet històric encara que potser no va ser el més representatiu o el de la primera presència del sector vitivinícola a la contrada que actualment és DO, com la DO Catalunya. 
En la taula 12, s'observa la distribució per DO. I usant els símbols del mapa, es veu la presència de la història de la vitivinicultura en els dissenys dels segells de la major part de les DO. És interessant pel valor que representa una DO, la qual es vincula a una societat, un territori i una identitat concretes. Que un segell d'un producte agrari de qualitat estigui representat per un període històric representatiu per l'arribada d'aquest producte a una societat o la seva importància en un moment determinat en mostra la rellevància.

El resultat final que s'ha obtingut amb aquest treball de recerca és que Catalunya és una terra on s'ha produit vi des de fa millennis i que algunes de les seves DO ho han recollit en el disseny del seu signe d'identificació i com a marca comercial, donant valor a l'elaboració ancestral d'un producte agrari.

\section{Bibliografia}

Bonnassie, P. (1979). Catalunya mil anys enrere. Creixement econòmic $i$ adveniment del feudalisme a Catalunya, de mitjan segle x al final del segle XI. Barcelona: Edicions 62. Camps i Arboix, J. (1969). Història de l'agricultura catalana. Barcelona: Editorial Tàber. Celestino, S.; Blánquez, J. (2007). «Origen y desarrollo del cultivo del vino en el Mediterráneo: la Península Ibérica», Revista Universum, 22, vol. I, p. 32-60.

Ciurana, J. (1980). Els vins de Catalunya. Barcelona, Servei Central de Publicacions de la Generalitat de Catalunya.

Estrabón (1995). Geografía (Hispania y Galia). Barcelona, Editorial Planeta Agostini, Llibre III, 4.16, p. 107.

FreIXAS, J. (1966). Història del comerç a Catalunya. Barcelona: Editorial Bruguera.

Furió, A. (2004). «L'utillatge i les tècniques», en GiRALt, E. (director) Història agrària dels Països Catalans. Volum II. edat mitjana. Barcelona: Fundació catalana per a la Recerca, Publicacions i Edicions de la Universitat de Barcelona, vol. II, pàgines 335-360.

Fuguet i SAns, Joan; Plaza Arqué, Carme. (2009). «Notícies històriques sobre la vinya i la varietat trepat a la Conca de Barberà». Dossiers agraris [en línia], p. 11-25, https://www. raco.cat/index.php/DossiersAgraris/article/view/248201 [Consulta: 31-03-2021]

Garcia-Oliver, F. «Els cultius», en Giralt, E. (director) (2004). Història agrària dels Països Catalans. Volum II. edat mitjana. Barcelona, Fundació catalana per a la Recerca, Publicacions i Edicions de la Universitat de Barcelona, vol. II, p. 301-334.

Heredia Bercero, B. de (dir.) (2001). De Barcino a Barcinona (segles I-VII). Les restes arqueològiques de la Plaça del Rei de Barcelona. Barcelona, Museu d'Història de la Ciutat, Institut de Cultura, Ajuntament de Barcelona, 249 p.

Huetz de Lemps, A. (2009). Les vins d'Espagne. Bordeaux, Presses universitaires de Bordeaux. Linares, G.; Fernández, M.; Fombella, J.; RuedA, J. (2013). Los Iberos: Aproximación a un conjunto de culturas prerromanas - Análisis arqueológico multidisciplinar.

López, C. (coor.) (2015), La Font de la Canya. Guia arqueològica. Jaciment ibèric de la Font de la Canya. Avinyonet del Penedès. Un centre de mercaderies a la Cossetània ibèrica origen de la vinya. Sant Sadurní d'Anoia, Institut d'Estudis Penedesencs. 
Martínez Tomé, A. (1991). El monasterio cisterciense en el origen de los vinos españoles. Madrid: Ministerio de Agricultura, Pesca y Alimentación.

Miró, J. (1988). La producción de ánforas romanas en Catalunya. Un estudio sobre el comercio del vino de la Tarraconense (siglos I a.C. - I d.C.). Coïmbra, Instituto de Arqueologia, Faculdade de Letras.

Molleví Bortoló, G. (2007). La geografía de la vid y el vino en Cataluña. Barcelona, Editorial Davinci Continental.

Museu Nacional Arqueològic de Tarragona (1998). Guia didàctica del Museu Nacional Arqueològic de Tarragona. Barcelona, Departament de Cultura, Generalitat de Catalunya. Puiny (1968): Natural History. Londres, William Heinemann, L.T.D.. Harvard University Press, vol. Iv, llibre xIv, p. 186-285.

QueSADA, F. (1994). Vino, aristócratas, tumbas y guerreros en la cultura ibérica (sS. V-II a.C.). Verdolay: Revista del Museo Arqueológico de Murcia, 6, p. 99-124.

Rexach, A. (2000). Vins i caves de Catalunya. Barcelona: Edicions L'isard.

SOLÀ, A.; FArRÉ, A. (redactors) (1979). «Història-I», Dolça Catalunya. Gran Enciclopèdia Temàtica Catalana. Barcelona, Ediciones Mateu, vol. v.

VAlLs, F. (2003). La Catalunya Atlàntica. Aiguardents $i$ teixits a l'arrencada industrial catalana. Vic, Eumo, 416 p.

Vilà Valentí, J. (1973). El món rural a Catalunya. Barcelona: Curial. 